NBER WORKING PAPER SERIES

OBSERVATIONS ON THE INDEXATION

OF OLD AGE PENSIONS

Lawrence H. Summers

Working Paper No. 1023

NATIONAL BUREAU OF ECONOMIC RESEARCH

1050 Massachusetts Avenue

Cambridge MA 02138

November 1982

The research reported here is part of the NBER's research program in Pensions. Any opinions expressed are those of the author and not those of the National Bureau of Economic Research. 


\section{Observations on the Indexation of old Age Pensions}

\section{ABSTRACT}

This paper examines some positive and normative aspects of the inflation indexation of public and private pensions. The analysis shows that alternative indexing arrangements may have far less impact on actual patterns of risk bearing than is usually thought to be the case. In so far as inflation indexing has real effects, there is no presumption that they are beneficial. In particular, the pre-commitment aspects of public indexing may not be efficient. There are sound reasons to believe that voluntarily agreed on, non-indexed private pensions may well be efficient. Non-indexed pensions may result in an efficient allocation of risks given the other assets and liabilities of pension issuers and beneficiaries. In this case, indexation would impede the efficient allocation of risks. In this paper is also developed an ICOLI (intertemporal cost of living index) which is superior to conventional price indices as a way of evaluating the changes in real well being, associated with changes in wealth. The use of this measure has significant implications for the indexation of pensions, and for the question of what assets should be held in pension portfolios.

Lawrence H. Summers

Council of Economic Advisers old Executive of fice Building 17 th \& Pennsylvania Avenue, N.W. Washington, D.C. 20506

(202) 395-5086 
A major issue in the desion of both public and private pension plans involves the indexation of benefits to price level chanes. A wajor purported virtue of current public pensions in the United States is that they provide an asset with a fixed real return. This is regarded as irportant because of the absence of an indexed bond warket. It is frequently alleged that the failure to provide indexed benefits is a major weakness of standard private pension arrangenents. These views have influenced the recomendations of groups such as the President's Commission on Pension Policy (1980) and the Advisory Council on Social Security (1979). Both these groups, without detailed aroument, strongly endorse the indexation of Social Security Benefits.

Serious consideration of issues regarding indexation requires the careful specification of an alternative to indexing. It is clearly naive to suppose that Social Security benefit levels would never be adjusted in the absence of indexation, or that real benefits would never be adjusted in the presence of indexing. It also requires recognition of three fundapental principles of modern finance. First, as exemplified by the Modigliani-Miller theorem, repackaging risk does not wake it go away. Provisions which insure pension recipients against some risks impose these same risks on the bearers of pension liabilities. Second, risk associated with an asset cannot be measured in isolation but depends on the covariance of its return with other economic events. Third, the consumers' objective is to reduce total risk, not to insulate themselves completely from any one source of uncertainty. While these principles are widely recognized, they have not informed many previous analyses of pension policy.

This paper examines some positive and nomative aspects of the inflation indexation of public and private pensions. A major conclusion of the analysis is that alternative indexing arrangements may have far less impact on actual 
patterns of risk bearing than is usually thought to be the case. In so far as inflation indexing has real effects, there is no presumption that they are beneficial. In particular, the pre-comitment aspects of public indexins may not be efficient. There are sound reasons to believe that voluntarily agreed on, non-indexed private pensions may well be efficient. Non-indexed pensions may result in an efficient allocation of risks given the other assets and liabilities of pension issuers and beneficiaries. In this case, incexation would impede the efficient allocation of risks.

Discussions of indexation in most contexts invariably focus only on inflation indexation. The reasons for this narrow focus are not clear. Consumers' objective is to minimize uncertainty about their well being not just to be free from inflation risk. It is certainly possible to imagine indexing public or private benefit levels to variables other than price indices. In this paper I develop an ICOLI (intertemoral cost of living index) which is superior to conventional price indices as a way of evaluating the changes in real well being, associated with changes in wealth. The use of this measure has significant implications for the indexation of pensions, and for the question of what assets should be held in pension portfolios.

The plan of the paper is as follows. The first.section analyzes the inflation indexation of public old age pensions. Under standard assumptions of either complete legislative discretion, or perfect capital markets, there will be no real effects arising from the indexation of Social Security benefits. If enough imperfections are introduced for indexation to have real effects, there is no presumption that they will be desirable. I argue that in the context of public pensions, indexation should be thought of primarily as a kind of "no real 
benefit cut" precommitment. Such a precommituent can have the perverse effect of holding down the size of the program.

The second section examines issues connected with the indexation of private pensions. Because of the non-coercive nature of private pensions, there are important differences from public pensions. Again, however, it is demonstrated that if capital markets are perfect, indexation of benefits will have no real effects. Once imperfections of a kind which permit indexing to have real effects are introduced, it is exceedingly unlikely that full indexing will be optinal. Indeed, some crude empirical calculations suggest that fixing nominal benefit levels may result in efficient risk sharing.

The third section of the paper extends the analysis by considering the possibility of indexing pensions benefits to variables other than the rate of inflation. There appear to be other sources of agzregate uncertainty which are of greater importance than inflation. A major source of uncertainty comes from fluctuations in the real rate of return which change the price of future consumption and so raise the sustainable standard of living. The merits of indexing benefits to a price index which includes the price of future consumption are assessed. The practicality of this proposal is exanined briefly.

The fourth and final section of the paper summarizes the results and examines their policy implications. A brief discussion of Robert Merton's proposal that Social Security benefits be indexed to agggregate consumption concludes the paper. 
I. Indexing Public Pensions

This section considers the effects of indexing the benefits in public pensions to the price level. Consideration of the possibility of indexing to an alternative agtregate matnitude is deferred to the third section. The analysis here focuses on the effects of chaneins the size of the program in response to changes in the price level. The issue of indexing in the design of benefit formulae is not considered.l

Since 1972, the Social Security program has in some sense been indexed to the price level.2 The indexation scheme initially enacted was conceptually flawed, and led benefits to rise much more rapidly than prices. The error was repaired in new legislation in 1977, which has been gradually phased in. At present, benefits for current recipients are indexed on an annual basis. In July of each year, benefits are increased by the annual rate of CPI inflation over the preceding 12 months. Several advisory groups including most recently, the President's Commission on Pension Policy have reconmended that the frequency of benefit adjustients be increased.

The argurents in favor of indexing the level of public pension benefits do not appear to be very well developed. The argument seens to be that indexing benefit levels provides insurance for beneficiaries against the effects of inflation. Little attention is given to the possibility that this insurance can be provided through private financial transactions. Frequently the consequences of alternative indexing arrangements for the risk characteristics of tax liabilities are not considered. Without considering these facets of the problem, it is impossible to evaluate the merits of indexing public pension benefits.

For clarity it is useful to consider the necessary conditions for indexing benefits to have any real effects at all. This is most easily done recognizing 
the following pair of "Indexing Irrelevance Propositions" for fublic pensions.

Proposition I. If bererits can be adjusted continuously to desired real levels, indexing arrangements will have no real effects on any economic variables.

Proposition II. If capital Earkets are perfect, and if private indexed bonds and norninal bonds exist, indexing érrargements will have no real efrects, even if benerits can be adjusted only periodically.

The first proposition is obvious once stated. Recardless of indexint arrargements, real benefits will be set at their desired level at each instant. The form of indexing arrangenent will affect whether benefit changes are or are not necessary, and their magnitudes, but will have no impact on real benerit levels. A similar argument sugests that in a colmpetitive spot labor market, indexing in wage contracts will have no real consequences. This proposition establishes that a necessary condition for indexation to have real effects is that benefits can only be adjusted periodically or that some types of legislated benefit adjustments (i.e., real benerit cuts) are not permitted. These possibilities are considered below.

The second proposition is equivalent to the Modigliani-Miller theorems for indexed bonds proved by Liviatan and Levhari (1977). It can be demonstrated as follows. Assume that a consumer has wealth $W_{O}$, which he allocates to consumption and various portfolio assets in order to waxirize

$$
\text { EU }\left(c, W_{T}\right) \text { s.t. } W_{T}=\Sigma\left(1+r_{i}\right) A_{i}+B
$$

where $C$ is consumption, $W_{T}$ is terminal wealth, $r_{i}$ is the real return on asset $i$, $A_{i}$ is investment in asset $i$, and $B$ represents real social security benefits which may be uncertain. Suppose for concreteness that asset 1 is the riskless indexed bond, and asset 2 is an otherwise riskless nominal bond. Then, when 
benefits are indexed, in order for then to have the same real value, the condition $B_{\text {nom }}=B_{\text {real }}^{\prime}\left(1+r_{2}\right) /\left(1+r_{1}\right)$ must hold. ${ }^{3}$ Now supposing that this condition does hold, consider any feasible allocation $(\hat{C}, \hat{A})$ when Social security is not indexed. The sane teminal wealth distribution can be obtained, if Social Security is indexed by taking $\stackrel{A}{A}_{1}=\hat{A}_{1}-B_{\text {real }} /(1+r), \hat{A}_{2}=\hat{A}_{2}+B_{\text {real }} /(1+r)$ and making no other portfolio chanees. A similar areurent can be used to show that switching from indexed to non-indexed benefits does not change the feasible set. It follows that indexing has no real effects under the stated conditions. The argument could be extended to consider taxpayers' behavior and show that indexing has no general equilibrium effects.

This proposition is clearly not literally applicable to the real world since indexed bonds do not exist. However it is an open question whether or not portfolios of assets with near constant real returns can be formed. If so the irrelevance proposition here will continue to hold. Even in the absence of indexed bonds, or the capacity to mamfacture thern from existing assets, individuals can undo the effects of non-indexation by borrowing to purchase real durable assets. Thus it seens likely that at least to the extent that individials have access to the capital markets, they can nesate many of the effects of indexing arrangeinents.

The preceding discussion demonstrates that capital market imperfections in conjunction with rigidities in adjusting benefit levels are a necessary condition for indexation to have real effects. We now consider the case where individuals have no access to indexed bonds or any close substitute and where benefits are subject to infrequent adjustment. 


\section{Indexation es Insurance}

If a program can be legislatively modified only infrequently, indexation of benefits will provide insurance against unexpected developwents between legislative adjustments. The importance of this insurance depends on the amount of unexpected variation in the price level which takes place between letislative adjustments. Table 1 reproduces a chronolozy of legislative chentes in Social Security Benefit forulae. It is clear from the table that benefit adjustinents are very conmon occuring on average every four years. It is useful to get an idea of how far out of line benerits can be over intervals of this length. The likely error in forecasts of the average price level over various horizons can easily be estilated. Forecasts based on estinates of expected inflation were generated by applying an ARMA $(1,1)$ process to annual rates of CPI inflation for the 1947-1975 period. The root mean square forecast error rises from 1.1 per- cent with a one year horizon to 4.2 percent with a five year horizon. These numbers do not suegest that indexation mitigates an otherwise important source of uncertainty and may seem surprisingly small. Suppose however that one misestinated the annual inflation rate over a 5 year period by three percent, the average error in estimates of the price level would only be 7.5 percent.

For two reasons, even these figures overstate the importance of any real uncertainties generated by the nonindexation of benefits. First, the timing of benefit readjustments is endogenous. When the price level innovation is large, adjustment of benefits can be accelerated. This means that one is unlikely to observe large undesired changes in real benefit levels. Second, and more important $l y$, benefit adjustments can take account of losses or gains suffered during the preceding period. For simplicity assume that the target level of real benefits is a constant $\bar{B}$. Now assune that benefits are adjusted each period. 
Act

1977

Mndificd to disiribute intal crediable wages in years 1937-50 over 1-14 years, with 4-14 increment ycars assumed. Table in the Act (as decmed cffeclive for Deccmber 1978) relating PIB's to PIA's frozen for wurkers who allain age 62 . hecome disabled, or dic after 1978. Cost-of-living adjustmenis applicable in year worker allained age 62 and afier, or if carlicr, year uniher hecame disahled or dicd applicd in Decemher 1978 PIA's. Effecilic for Junc 1979. increasc of $9.9 \%$ in current bencfil levels. Effective for June 1950, increase of 14.3\% in curreni benefil levels. Eg colive for June 1981 , inciease of $11.2 \%$ in current henefit levels.

[Formula applics to AMP computed for perind afier 1950]

$195050 \%$ of first $\$ 100$ plus $15 \%$ of riex: $\$ 200$. Effective for April 1952.

$195255 \%$ of first $\$ 100$ plus $15 \%$ of nex $\$ 200$. Effective for Sepicmber 1952. incrcase of $12 \mathrm{k} \%$, but not less than $\$ S$ in current hencfit levels.

$195455 \%$ of firsi $\$ 110$ plus $20 \%$ of nex $\$ 240$. Effective for Scptember 1954. increase of at least $\$ 5$ (current bencfit levels increased by approximately $13 \%$ ).

IUnderlying formula appearing (or dcemed to appear) in able in the Act]

$195858.85 \%$ of first $\$ 110$ plus $21.40 \%$ of nexi $\$ 290$. Effcrive for Jonuory 1959, increase of the greater of $7 \%$ or $\$ 3$ in bencfit level.

$196562.97 \%$ of first $\$ 110$ plus $22.90 \%$ of nexi $\$ 290$ plus $21.40 \%$ of next $\$ 150$. Effecrive for January 1965. increase of the greater of $7 \%$ or $\$ 4$ in bencfit level.

$196771.16 \%$ of firsi $\$ 110$ plus $25.88 \%$ of ncxi $\$ 290$ plus $24.18 \%$ of ncxt $\$ 150$ plus $28.43 \%$ of next $\$ 100$. Effective for February 1968, increase of at least 13\% in bencfit level.

$196981.83 \%$ of first $\$ 110$ plus $29.76 \%$ of next $\$ 290$ plus $27.81 \%$ of next $\$ 150$ plus $32.69 \%$ of next $\$ 100$. Effrctive for Januon, 1970, increase of at least 15\% in henefit level.

$197190.01 \%$ of first $\$ 110$ plus $32.74 \%$ of nexi $\$ 290$ plus $30.59 \%$ of nex $\$ 150$ plus $35.96 \%$ of nex $\$ 100$ plus $20 \%$ of nexi $\$ 100$. Effective for Januory 1971 . increase of $10 \%$ in henchit level.

1972a $108.01 \%$ of first $\$ 110$ plus $39.29 \%$ or next $\$ 290$ plus $36.71 \%$ of nexi $\$ 150$ plus $43.15 \%$ of nexi $\$ 100$ plus $24 \%$ of next $\$ 100$ plus $20 \%$ of nexi $\$ 250$. Efferive for September 1972. increase of 20\% in bencfit level. (Provision for future automatic "cost-ofliving" increases.)

1973a $114.38 \%$ of first $\$ 110$ plus $41.61 \%$ of next $\$ 290$ plus $38.88 \%$ of nexi $\$ 150$ plus $45.70 \%$ of next $\$ 100$ plus $25.42 \%$ of next $\$ 100$ plus $21.18 \%$ of next $\$ 250$ plus $20 \%$ of next 550 . Effecrive for June 1974 through December 1974 hut never applicable. Increase of $5.9 \mathrm{~m}$ in benefit level eliminated by $1973 \mathrm{~b}$ legislation.

$1973 \mathrm{~h} 119.89 \%$ of first $\$ 110$ plus $43.61 \%$ of next $\$ 290$ plus $40.75 \%$ of nexi $\$ 1.50$ plus $47.90 \%$ of nexi $\$ 100$ plus $26.64 \%$ of next $\$ 100$ plus $22.20 \%$ of next $\$ 250$ plus $20 \%$ of next $\$ 100$. Increase of $11 \%$ in 1972a bencfit levels, effective in 2 sleps: Tro. for March-May 1974: 4. additional, for June 1974. (Bcginning Junc 1975. subject to automatic "cost-of-living" increase. under modification of 1972 provision.) Plus 20\% of next \$75. effective for January 1975.

$129.48 \%$ of first $\$ 110$ plus $47.10 \%$ of next $\$ 290$ plus $44.01 \%$ of nexi $\$ 150$ plus $51.73 \%$ of nexi $\$ 100$ plus
Act

$28.77 \%$ of nexi $\$ 100$ plus $23.98 \%$ of $n e x 1 \$ 250$ plus $21.60 \%$ of next $\$ 175$. Effective for June 1975 . increasc of $8 \%$ in bencfit level. Plus $20 \%$ of next \$100, effective for January 1976.

$137.77 \%$ of first $\$ 110$ plus $50.10 \%$ of next $\$ 290$ plus $46.82 \%$ of next $\$ 150$ plus $55.05 \%$ of next $\$ 100$ plus $30.61 \%$ of next $\$ 100$ plus $25.51 \%$ of next $\$ 250$ plus $22.98 \%$ of nexi $\$ 175$ plus $21.28 \%$ of next $\$ 100$. Effecrive for June 1976, increase of $6.4 \%$ in henefit Icvel. Plus $20 \%$ of nexi $\$ 100$, effecrive for Jonuary 1977.

$145.90 \%$ of first $\$ 110$ plus $53.06 \%$ of nex $\$ 290$ plus $49.58 \%$ of nexi $\$ 150$ plus $58.30 \%$ of riex $\$ 100$ plus $32.42 \%$ of nex $\$ 100$ plus $27.02 \%$ of nex $\$ 250$ plus $24.34 \%$ of nexi $\$ 175$ plus $22.54 \%$ of nex $\$ 100$ plus $21.18 \%$ of next $\$ 100$. Effective for June 1977. increase of $5.9 \%$ in bencfit level. Plus $20 \%$ of next $\$ 100$. effective for January 1978 .

$155.38 \%$ of first $\$ 110$ plus $56.51 \%$ of next $\$ 290$ plus $52.81 \%$ of next $\$ 150$ plus $62.09 \%$ of $n e x 1 \$ 100$ plus $34.53 \%$ of nexi $\$ 100$ plus $28.78 \%$ of nexi $\$ 250$ plus $25.92 \%$ of nexi $\$ 175$ plus $24.01 \%$ of nex $\$ 100$ plus $22.56 \%$ of next $\$ 100$ plus $21.30 \%$ of next $\$ 100$. Effecrive for June 1978, increase of $6.5 \%$ in benefit level.

1977 For workers who attain age 62, become disabled, or die before 1979: formula same as preceding formula plus $20 \%$ of next $\$ 435$. cffective for January 1979.

$170.76 \%$ of first $\$ 110$ plus $62.10 \%$ of next $\$ 290$ plus $58.04 \%$ of next $\$ 150$ plus $68.24 \%$ of next $\$ 100$ plus $37.95 \%$ of nexi $\$ 100$ plus $31.63 \%$ of $n e x 1 \$ 250$ plus $28.49 \%$ of next $\$ 175$ plus $26.39 \%$ of nex $\$ 100$ plus $24.79 \%$ of nexi $\$ 100$ plus $23.41 \%$ of next $\$ 100$ plus $21.98 \%$ of next \$435. Effective for June 1979. incicase of $9.9 \%$ in benefil level. Plus $20 \%$ of nexi \$250. effecrive for Jonuary 1980.

$195.18 \%$ of first $\$ 110$ plus $70.98 \%$ of nexi $\$ 290$ plus $66.34 \%$ of nex $\$ 150$ plus $78.00 \%$ of next $\$ 100$ plus $43.38 \%$ of nexi $\$ 100$ plus $36.15 \%$ of nexi $\$ 250$ plus $32.56 \%$ of nexi $\$ 175$ plus $30.16 \%$ of nex $\$ 100$ plus $28.33 \%$ of nex $\$ 100$ plus $26.76 \%$ of nex $\$ \$ 100$ plus $25.12 \%$ of next $\$ 435$ plus $22.86 \%$ of next $\$ 250$. Effective for June 1980. increase of $14.3 \%$ in benefit icvel. Plus 20\% of next \$315, effective for January 1981 .

$217.04 \%$ of first $\$ 110$ plus $78.93 \%$ of nex $\$ 290$ plus $73.77 \%$ of nex $\$ 150$ plus $86.74 \%$ of nex $\$ 100$ plus $48.24 \%$ of nexi $\$ 100$ plus $40.20 \%$ of next $\$ 250$ plus $36.21 \%$ of nex $\$ 175$ plus $33.54 \%$ of next $\$ 100$ plus $31.50 \%$ of next $\$ 100$ plus $29.76 \%$ of next $\$ 100$ plus $27.93 \%$ of next $\$ 435$ plus $25.42 \%$ of next $\$ 250$ plus $22.24 \%$ of next $\$ 315$. Effective for June 1981 . increase of $11.2 \%$ in benefit level.

\section{[Formula applies to AIME]}

1977 For workcrs who atrain age 62, become disabled or dic in 1979: $90 \%$ of firsi $\$ 180$ plus $32 \%$ of next $\$ 905$ plus 15\% of excess over \$1.085. Effective for Jorluory 1979. (Provision for future automatic increases in bend mints, \$180 and \$1.085, and for future automatic "cest-of-living" increases after cligibility for benefis.) Effective for June 1979. increasc of $9.9 \%$ in henefit level. Effective for June 1980, incrcase of $14.3 \%$ in benefit level. Effecsive for June 1981, incrcase of $11.2 \%$ in benefit level.

For workers atlaining age 62 in 1979-83 and applying for old-age retirement benefits or dying in or afier 
Then suppose that in each period benefits are set to satisfy the expression:

$$
E\left(B_{t}\right)=\bar{B}+(1+r)\left(B_{t-1}-E\left(B_{t-1}\right)\right)
$$

It follows that:

$$
\sum_{1}^{T} \frac{B_{t}}{1(1+r)^{t}}=\frac{T}{L}-\frac{\bar{B}}{(1+r)^{t}}+\frac{\left(B_{T}-\bar{B}\right)}{(1+r)^{T}}
$$

That is the uncertainty in the present value of benefits received by an individual, the second term is (3), is much sraller than the uncertainty associated with benefits in any given year.

Assuming that individuals have a capacity to borrow and lend at the interest rate $r$, in Equation (2), the reduction in lifetime risk due to indexing is clearly negligable. Some data on the financial position of the elderly are presented below. They show that most possess at least a small amount of liquid assets. That is all that would be necessary to buffer any fluctuations in real income due to unexpected chantes in the price level. Even for incividuals with no access to the capital rarket, there is some rargin for interteporal substitution in the timing of the purchases of durable goods. It thus $s=$ ers unlikely that the length of the adjustrent period constitutes any significast areument for indexation. The data in Table 2 certainly suggest that there jas been no reduction in the variance in real benefit levels in the post 1972 Eeriod when Social Security was indexed. Admittedly this evidence is difficuI= to interpret because there has been an upward drift in benefit levels.

\section{Indexation as Precomitment}

None of the foregoing discussion suggests arv large effect of a policy of indexed benefits. Yet the issue seens to be viewed passionately $=$ =ary 
TABLE 2

: Ratios of Primary Benefit for Man Retiring At Age 65

At Beginning of Various Years To Earnings

In Year Before Retirement

\begin{tabular}{|c|c|c|c|}
\hline Year & $\begin{array}{l}\text { Low-Earnings } \\
\text { Individual }\end{array}$ & $\begin{array}{c}\text { Average-Earnings } \\
\text { Individual }\end{array}$ & $\begin{array}{c}\text { Maxirnum-Earnings } \\
\text { Individual }\end{array}$ \\
\hline 1953 & $53.5 \%$ & $30.7 \%$ & $28.3 \%$ \\
\hline 1954 & 51.9 & 29.3 & 28.3 \\
\hline 1955 & 54.8 & 34.3 & 32.8 \\
\hline 1956 & 53.8 & 33.5 & 29.6 \\
\hline 1957 & 52.3 & 32.5 & 31.0 \\
\hline 1958 & 50.8 & 31.9 & 31.0 \\
\hline 1959 & 52.7 & 33.5 & 33.1 \\
\hline 1960 & 51.8 & 32.8 & 29.8 \\
\hline 1961 & 49.6 & 31.7 & 30.0 \\
\hline 1962 & 48.8 & 31.3 & 30.2 \\
\hline 1963 & 46.8 & 30.3 & 30.5 \\
\hline 1964 & 46.4 & 29.8 & 30.8 \\
\hline 1965 & 48.9 & 31.5 & 32.9 \\
\hline 1966 & 48.1 & 31.3 & 33.2 \\
\hline 1967 & 52.1 & 34.2 & 27.9 \\
\hline 1968 & 49.7 & 32.4 & 28.4 \\
\hline 1969 & 47.1 & 30.8 & 24.7 \\
\hline 1970 & 52.2 & 34.3 & 29.2 \\
\hline 1971 & 51.5 & 34.3 & 29.2 \\
\hline 1972 & 52.3 & 34.9 & 33.2 \\
\hline 1973 & 58.4 & 39.4 & 35.5 \\
\hline 1974 & 56.3 & 38.3 & 30.5 \\
\hline 1975 & 59.7 & 40.7 & 28.8 \\
\hline 1976 & 60.6 & 42.4 & 31.0 \\
\hline 1977 & 61.8 & 43.6 & 32.4 \\
\hline 1978 & 62.1 & 44.4 & 33.4 \\
\hline 1979 & 62.1 & 45.3 & 34.1 \\
\hline 1980 & 64.2 & 47.1 & 29.9 \\
\hline
\end{tabular}

Note: Earnings record for average-earnings individual is the annualized average wage for all workers in the first quarter of the particular years. Earnings record for low-earnings individual is $\$ 3,200$ for 1974 ; for other years, it is the same ratio to the earnings of the average-earnings individual as prevailed in 1974 (narnely, 39.8\%).

Note: The lower ratios for the average-earnings individual than for the inaximurn-earnings one in 1963-66 result from the fact that, because the inaxirnurn taxable earnings base remained unchanged in 1959-65, the former had almost the same "final" earnings as the latter, but had significantly lower "career" earnings.

Source: Robert J. Myers, "Summary of the Provisions of the Old-Age, Survivors, and Disability Insurance System, the: Hospital Insurance System, and the Supplemental Medical Insurance System." Temple University, June 1980. 
interest groups. One plausible explanation of how indexation can have inportant effects comes from viewing it as a form of pre-comituent. The government is comintted because of political constraints to maintain the level of benefits, however they are denominated. If benefits are indexed, they cannot be cut in real terns. If not indexed, they cannot be cut in nominal terms. This distinction is frequently cited in discussions of tax bracket indexing as well as Social Security indexing. It may be the result of any political process in which it is difficult to enact legislation, because more than a majority is required, or the problems of consensus building among diverse constituencies. In this situation, it is possible to reduce real benefit levels through inflation erosion, and inaction but not through actual legislation. Thus the main effect of indexation may be to pre-comnit to a minimum fixed real bersefit level.

At first, it may seem as if such a policy should be favored by advocates of a larger Social Security systen. Indexation does prevent reductions in real benefit levels through inflation. Upon reflection however, the situation is more complex. The optimum level of real benefits legislated will in general be lower if a constraint is imposed precluding future benefit reductions. The nature of the ambiguity can be highlighted in the context of a highly stylized model.

Suppose that optimm level of benefits in period $t$ is given by $x_{s}$ where $X_{S}$ is distributed uniformly on the unit interval and is serially uncorrelated. As sume also that the regret associated with setting a benefit level $B_{S}$ in period $t$ is given by:

$$
\begin{aligned}
& R(\underline{B}, X)=X-B \quad \text { if } \quad B \leq X \\
& =a(B-X) \text { if } \quad B \geq X
\end{aligned}
$$


Let policy maiers design the Social Security schene to minimize the present value of future regrets. That is they choose a sequence of values $B_{S}$ in each period to minimize:

$$
L=E \sum_{t}^{\infty} R(B-X) B(s-t)
$$

In the case where there is no precomitiont problem, the optiual stratedy is clearly to set $B_{S}=X_{S}$ in each period and have zero regret. Wote that when this strategy is followed, the wean level of benefits is $\bar{X}=.5$.

Now consider the optimal strategy when benefits can never be cut. It is inmediately obvious that it will never be desirable to set $B_{S}>X_{S}$. However it ray be desirable to set $B_{S}<X_{S}$. This nay be seen as follows. Let $L(\underline{B})$ be the expected regret if the optimal strategy is pursued, given that benefits are constrained to be greater than $\underline{B}$ in all remaining periods. Then it follows imme- diately that if $X_{S} \leq \underline{B}_{S}$ that the optimal strategy is to set $B_{S}=B_{S}$. If $X_{S} \geq B_{S}$, the optinal strategy is to set $B_{S}=x_{S}$ or to satisfy the first order condition:

$$
1-B\left(\frac{d L}{d \underline{B}}\right)_{\underline{B}=B_{S}}=0
$$

if the value of $B_{s}$ satisfying this first order condition is less than $X_{s}$. The first order condition (6) states that the marginal gain from increasing benefits in the current period, must equal the marginal cost from irmosing tighter constraints in future periods. The first order condition (6) does not provide a basis for computing the optimm level of $B_{t}$, since the form of the function $L($ B) is unknow. 
However it is possible to characterize the stochastic steady state when the optimal strategy is pursued. This may be done as follows. The optimura feasible strategy at time $s$ is given by some function $B_{S}=f\left(\underline{B}_{S}, X_{S}\right)$ which is clearly monotone increasing in $X_{S}$. The raximam attainable value of $X_{S}$ will be given by $\mathbf{f}\left(\underline{B}_{t}, 1\right)$, which as shown below does not depend on $\underline{B}$. It is clear that ultivately the value of $B_{t}$ must approach this limit. The steady state may then be characterized by solving for $\mathrm{f}(\underline{B}, 1)$.

Equation (6) reveals that the optimurn choice of $B^{*}$ does not depend on $\underline{B}$. It can be solved easily in this case. Suppose $f(\underline{B}, l)=B^{*}$. Then in all future periods $B=B^{*}$. If $X<B^{*}$, the "no-cut constraint" insures this equality. If $X>B^{t}$ the equality is insured by the monotonicity of the function $f(\underline{B}, X)$. This means that it is easy to evaluate $f\left(B^{*}\right)$. It is given by:

$$
E \sum_{0}^{\infty} B^{t} R\left(B^{*}\right)=E \frac{\left[R\left(B^{*}\right)\right]}{1-B}
$$

Differentiating (7) and using (6) yields the first order condition:

$$
1-\frac{B}{1-B}\left(B^{\star}(1+a)-a\right)=0
$$

It follows that $B^{*}$ is given by:

$$
B *=\frac{1-B}{B(1+a)}+\frac{a}{1+a}
$$

Several inferences can be drawn from equation (9). Note first the steady state level of benefits $B^{*}$ can be $g$ reater or less than the expected benefit level when full discretion is maintained. By choosing appropriate parameter values. in (9) any level of $B$ may be found to be optimel. As the value of the discount factor $B$, increases, the level of benefits declines. This is because when the 
future counts more highly, the cost of constraining one's policy choices is more severe. As one would expect, increases in the value of a also reduce the steady state value of $B$.

The stylized model here illustrates an obvious principle trat cutting off one's options is undesirable, and a more subtle one that irposing a "no-cut" constraint on a profram may reduce its expected funding level. Obviously, the model would accoisodate a nurber of extensions. But it seens unlikely that these qualitative results would be upset by introducing factors such as an upward drift in the expected desired level of funding $x_{s}$ or allowing it to be serially correlated.

It is difficult to assess the relevance of the effects stressed here. Certainly the current policy debate on Social Security wakes it plausible that the program would be cut in real terms, if this were possible without legislative action. This suggests the importance of the pre-comitment aspect of indexation stressed here. The failure of Congress to rescind double indexing's effects strongly supports the importance of pre-comitxent effects. Whether or not "no cut" commitments have the restraining effects on spending susgested here is more problematic. 
II. Inflation Indexption and Private Pensions

There are at least two important indexation issues in connection with defined benefit private pensions. First, there is the question of indexing benefits for persons who are already retired. At the present time, most private pensions in the United States provide beneficiaries with level nominal annuities. While adjustments are sometines made for the effects of inflation, these are rare and relatively small. A second issue is in the calculation of benefits. At present, in most plans, workers' vested benefits are a fraction which depends on years of service and their current salaries. Actual benefits received from a firm depend on a worker's final year salary at that firm. These two aspects of pension indexation are considered separately below.

\section{Indexed Retirement Benefits}

It is widely believed that private pensions should offer indexed retirement benefits. For example, the President's Comisission on Pension Policy (1980) "... encourages private and state and local pension plans to provide some form of inflation protection for retirees." The failure of private pensions to offer indexed options is a puzzle. Feldstein (1981) suggests the develogwent of indexed pensions would not have been desirable because workers already had a substantial degree of inflation protection from Social Security. His analysis assumes that the capital market corpensates individuals for bearing inflation risk. The basis for this supposition is not at all clear. Both the issuers and holders of nominal instruments bear risk from inflation uncertainty. There is no obvious reason why the holders rather than issuers of nowinal instruments should be compensated for bearing this risk. Indeed, the fact that mean 
realized returns on bonds and bills have been essentially zero over the last 50 . years tends to susgest that the capital warket does not compensate individuals for bearing inflation risk.

At the outset, it is useful to consider as a benchnark the special case of a perfect capital market, in the presence of a safe real asset, and unchanging opportunity sets for investors. In this case all individuals in equilibrium will hold some combination of the safe asset and the market portfolio. There is no optimal degree of pension indexing; any form of pension asset is as good as any other. If a firm issues safe real pensions, it will find that its shareholders hedge by purchasing the safe asset. Its pension beneficiaries draw down their holdings of the safe asset and switch their portfolios towards more risky assets. The form of the pension benefit is a matter of irrelevance. This theorem can clearly be proven under much more Eeneral assumptions, similar to those that have been used to provide proofs of the generalized Modigliani-Miller theorems. In order to find any effects of alternative indexing arraneenents, it is necessary to introduce some capital market irerfections.

The natural imperfection to introduce is a restriction on short sales. This has at least two potentially important effects. First, it may be impossible for individuals to undo the effects of their pension plan. In general, this would require drawing down or selling short their assets held by their pension funds. This consideration, taken by itself would tend to suggest that efficient private pension arrangements would wake benefit levels contingent on the returns on widely traded assets. Second, in general it will be iupossible for all individuals to hold the market portfolio. Because of moral hazards, individuals are likely to be locked into holding much more of their wealth in the form of their own homes and human capital, than would be included in fully diversified port- 
rolios. This suejests that they would prefer their persion assets to have returns that are negatively correlated with the returns on assets that they are locked into holding. ..

Hurd and Shoven (1982) assess the vulnerability of the portfolio of assets held by the elderly to the efrects of inflation. They conclude that even when nominal pensions are included, the aged are for the rost part well hedeed against unexpected inflation. It is likely that their results understate the extent to which the aged are protected frow inflation. A very sizable fraction of the wealth of the aged is represented by the Eross value of their homes. Both economic theory and erpirical evidence, (Sumrers (1981a,) Poterba (1981)) suggest that owner occupied housing prices should rise wuch more than point for point with unexpected inflation. This inference is supported by the recent sharp decline in real house prices.

These factors sügest that noninal pension liabilities may in fact reduce the real uncertainties associated with the wealth position of the aged. of course efficient pension arrarberent cannot be discussed without also considering the risks borne by corporate shareowners. This aspect of the problem is considered below, after a discussion of the role of indexation in vesting provisions.

Indexed Vesting Provisions

Bulow (1982) has made the important observation that in a competitive labor market a worker's marginal product in each period should equal the sum of his wate and his accrual of vested pension benefits. More generally, his arement suggests that some set of market forces determine an optimal time path for compensation. This optimal compensation path will in gereral be independent of what pension arrangements are made. If pension benefits are vested in nomi- 
nal terns, they represent a nominal asset to workers, and nominal liability to firms. If the rate of inflation. rises, the value of the vorker's already accrued yension asset "declines. There is no reason why this should be associated with hieher subsequent corpensation anymore than one would expect workers' colmpensation to be increased just because other parts of their portfolio performed badly

The conton argument that pensions are effectively indexed during the accrual phase, because benefits are tied to final year salaries, is as Bulow points out, wrong. It ignores the fact that wages and pension accruals are determined jointly. Market forces determine a path of total compensation not a path of wases. If inflation increases, and pension rules remain static, so that the rate of browth of pension accruals increases, the rate of wage growth will decline.

Thus under current institutional arrangenents, pension wealth is a nominal asset for all workers, not just those who have already retired. At current high rates. of interest, the value of the asset is likely to be sinall for most young workers. As just erphasized we should not expect the non-indexation of vested benefits to have any effect on the path of compensation. Hence there is no reason to expect that indexing pensions would have and effects on patterns of labor turnover or allocative efficiency. Again by the same arguments made above, in a perfect capital market indexation would have no real effects.

Table 3 presents some evidence on the balance sheets of different age groups. The data suggest that the younger part of the population is likely to be even better hedjed against inflation than the aged. This inference is strengthened by the observation that the "net hone" iter in Table 3 is likely to 


(1)

TABLE 3

Composition of Wealth by Age Group December 31, 1962

(Percentage distribution of dollar aggregates)

\begin{tabular}{|c|c|c|c|c|}
\hline \multirow[b]{2}{*}{ Form of Wealth } & \multicolumn{4}{|c|}{ Age of Head } \\
\hline & $\begin{array}{l}35- \\
44\end{array}$ & $\begin{array}{l}45- \\
54\end{array}$ & $\begin{array}{l}55- \\
64\end{array}$ & $\begin{array}{l}65 \text { and } \\
\text { over }\end{array}$ \\
\hline Total & 100 & 100 & 100 & 100 \\
\hline Net home & 31 & 33 & 25 & 22 \\
\hline Automobile & 5 & 4 & 2 & 1 \\
\hline Business & 23 & 23 & 20 & 12 \\
\hline Liquid assets & 10 & 11 & 13 & 16 \\
\hline Investment assets & 22 & 26 & 38 & 47 \\
\hline Miscellaneous assets & 9 & 3 & 2 & 1 \\
\hline
\end{tabular}

Source.--Dorothy S. Projector and Gertrude S. Beiss, Survey of Financial Characteristics of Consumers (Board of Governors of the Federal Reserve System, August, 1966). 
involve much nore offsetting gross ho:se value and morteage debt for younger households. This implies that the provision of nominal pensions is unlikely to impose serious risks on young workers.

\section{Risk Bearing By Firms}

The question which remains to be exanined is the impact of alterrative pension indexing arrangererts on the risis borne by the ultimate cwners of pension liabilities. The proximate owners are corporation. The ultinate owners are mainly corporate shareowners, but also other corporate creditors, and taxpayers through the PBGC. Given capital market imperfections, it is reasonable to expect that corporate shareomers vill be less well hediged against inflation than will pension beneficiaries. Data in Blume, Crockett and Friend (1974) confirm that ownership of corporate stock is concentrated among the very affluent. Hurd and Shoven report that inflation vulnerability increases with affluence. This inference is strongly confirmed by the data in Table 4 on the corposition of wealth by income class. The share of liquid assets and investisent assets (mainly stocks and bonds) rises sharply with income.

The saine point way be made more directly. Despite the fact that pension liabilities are nominal, corporate equity returns are systematically negatively related to unexpected inflation. In Sumers (1981b) I show that this is quite consistent with rationality on the part of investors. A one percent increase in the permanent rate of expected inflation is estimated to reduce the present value of real cash flows to shareholders by 3.46 percent, due to tax effects. This calculation does not take any account of pension obligations. Since in most cases pension plans are overfunded, taking account of pension assets and liabilities would increase the estinated negative effect of inflation. If firms 


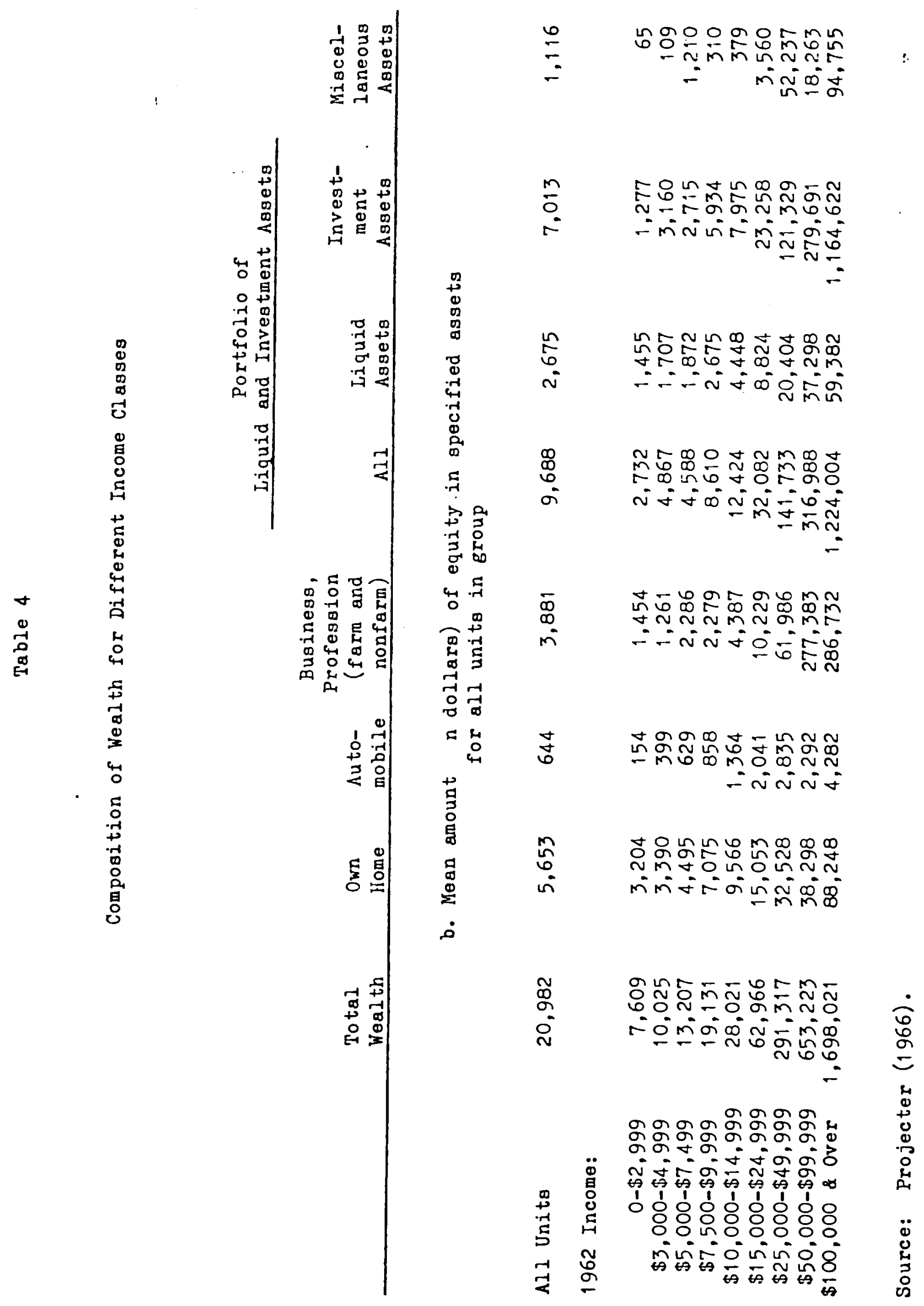


offered indexed pensions, the nesative effect would be increased still further. The discussion in this section sugtests that the failure of the private market to develop inflation indexed pensions is not surprising. In a perfect capital rarket, indexation arrangerrents would have no real effects. If capital markets are imperfect, one would expect arrangements to evolve which lead to the sharing of otherwise undiversifiable risks. The holders of pension assets appear to be positioned so that they gain from unexpected inflation. The corporations which issue pension liabiities appear becalse of a non-indexed tax system to be in the position of nominal creditors. This means that efficient risk sharing calls for the issuance of nominal pension liabilities. It is interesting to note that similar considerations can explain why indexed bonds have not been issued. 


\section{Indexing to Other Algrecates}

Almost all p'ractically oriented discussions of indexation focus on indexing benerits to the general price level. The notivation for this choice is rarely clearly specified. The implicit artument for price level indexation seems to be that this provides full insurance because real benefit levels are guaranteed. To state this arsument is to realize its limitations. Presurably, we care about the real standard of living of pension and Social security beneficiaries, rather than their benefit levels frow the proframs. Only for indiviciuals wholly supported by a given non-adjustable program is there a potential arsunent for inflation indexation of benefit levels. The discussion in the preceding section made the point that insuring progran benefit levels may actually increase the risk borne by beneficiaries if benefits would otherwise have covaried negatively with the assets in beneficiaries' portfolios.

This raises the more general point, that if the goal is to provide insurance to beneficiaries, it will in general be desirable to link changes in benefits to changes in the opportunity set faced by consimers. Eenefits should be varied so as to play the role of the hedise portfolios in Merton's (1973) Intertemporal Capital Asset Pricing Model. Of course, the qualifications suggested in preceding sections about whether indexing can have any real effects apply equally in this context. Similarly the cost of ary insurance is that the insured risks are foisted on the holders of pension liabilities.

These points may be illustrated in a more formal way. Consider the problem of the representative aged consumer. For simplicity, I assume that the horizon is known with certainty, and that future prices are known with certainty, so that there exists a safe real asset. The consumer's problen is to: 


$$
\operatorname{Max} \int_{t}^{T} U\left(C_{s}\right) e^{-\delta(s-t)} d s \quad s \cdot t \cdot A_{t}+\int_{t}^{T} B_{s} e^{-1(s-t)} d s=\int_{t}^{T} P_{s} C_{s} e^{-1(s-t)} d s
$$

where A represents assets, B represents benefits, and $i$ is the nominal interest rate. This problem gives rise to an indirect utility function of the form:

$$
U=V\left(A_{t}, i, P_{t} \ldots P_{T}, B_{t} \ldots B_{T}\right)
$$

It is not difficult to verify that the indirect utility function (11) is honogeneous of degree $O$ in $A$ and the vectors $P$ and $B$. If for siuplicity it is assuned that the rate of inflation is constant, (11) can be rewritten as:

$$
U=H\left(\frac{A_{t}}{P_{t}}, 1_{t}-\pi, b_{t} \cdots b_{T}\right)
$$

where $\pi$ is the rate of inflation and the lower case values of $B$ represent real benefit levels. It is inmediately apparent from (12) that chanies in the rate of inflation will not affect the attainable level of utility only if (i) they do not affect real benefit levels, $B_{t}$, (ii) they leave the real interest rate $i_{t}-$ $\pi_{t}$, unaffected and (iii) they have no effect on real wealth. Conventional indexing schemes are directed at insuring that the first of these conditions is met. The discussion in the preceding section considered the implications of the fact that ( $i i 1)$ is unlikely to be satisfied. The analysis here however suggests that indexing if it is to insure beneficiaries' standard of living must take account of all changes in real wealth, and in the real interest rate. The effect of chanjes in the real interest rate is of particular interest. 
Conventional price indices try to measure the change from period to period in the cost of attaining some level of utility. Normaly, this is done by finding the change in the purchase price of a fixed bundle of goods. The logic of this procedure is not clear once one recobnizes that consuners "spend" most of their income on future consumption. If the price of a washing rachine goes down a consumer is usually though better off. Has he not also gained if the price in terms of today's dollars of the bundle he plans to buy next period goes dorn? This suggests that in evaluating the welfare of the aged some sort of intertemporal price index should be emploged.

There is another way of looking at the problem which leads to a sinilar conclusion. Consider an individual who desires a constant real consurption stream, and holds all his wealth in the form of an indexed real annuity. Such an individual is exposed to no real risk since his annuity pajments exactly match his consunption stream. However if real interest rates fluctuate, the Inarket value of such a real annuity will vary. The asset will appear risky when risk is keasurable in the standard way. This paradox is easily resolved. When real interest rates rise, the value of the annuity declines and the price of future consumption also falls. The value of the annuity measured relative to a proper intertemporal cost of living index (as described below) remains constant. Notice that the same analysis could be applied to the situation of an individual who owns his home which fluctuates in value as the real interest rate changes.

Pollak (1975) shows how the standard theory of cost of living indicies can be extended to intertemporal case. The goal here is more modest. In an effort to illustrate the potential inportance of changes in the real interest rate, I 
calculate altérnative estinates of a Laspyres intertemporal cost of living index. The assumed market basket is a constant stream of real consumption over a 10 year period. The purchase price of such a real annuity is given by:

$$
P_{A}=\frac{P_{t}\left(1-e^{-r_{t} T^{T}}\right)}{r_{t}}
$$

where $r_{t}$ is the real interest rate at tine $t$, and $T$ is the annuity horizon. The change in the interterporal cost of living index is given by:

$$
\% \Delta P_{A}=\% \Delta P_{t}+\% \Delta \frac{\left(1-e^{-r_{t} T^{T}}\right)}{r_{t}}
$$

The first term in (14) corresponds to the ordinary inflation rate. The second corresponds to the change in the price of future consumption.

The wajor problem in estimating the intertenporal price index given in (13) is measuring the long term real interest rate. In the empirical work reported below, the actual ex-post rates of inflation were used in calculating the long term real interest rate. For periods after 1981 , when actual inflation data were unavailable, expected inflation as measured in the Livingston Survey was used. This data is described in Carlson (1977). Obviausly, the use of such a perfect foresight inflation reasure is somerhat problematic. Preliminary investigations using the econouetric reasures of expected inflation developed in Sumers (1981a) reached qualitatively similar conclusions.

Estinates of the percentage change in the intertemporal cost of living index are shown in Table 5 elong with the rate of CPI inflation. It is clear that movements in real interest rates are an important eleruent affecting the intertemporal index. In the three years when CPI inflation was greatest, 1974 , 1978, and 1979, the interte:poral index showed only very small increases. This 


\section{Alternative Cost of Living Indices}

$\begin{array}{lrr} & \text { \% } \Delta \mathrm{CPI} & \% \Delta \mathrm{P} \\ 1953 & 0.637 & -0.151 \\ 1954 & 0.501 & 1.424 \\ 1955 & 0.359 & 0.357 \\ 1956 & 2.862 & 1.977 \\ 1957 & 3.019 & 1.076 \\ 1958 & 1.771 & 3.672 \\ 1959 & 1.508 & 0.110 \\ 1960 & 1.478 & 3.628 \\ 1961 & 0.671 & 3.034 \\ 1962 & 1.215 & 1.982 \\ 1963 & 1.661 & 5.215 \\ 1964 & 1.216 & 5.645 \\ 1965 & 1.935 & 4.318 \\ 1966 & 3.348 & 1.759 \\ 1967 & 3.041 & 3.768 \\ 1968 & 4.718 & 4.172 \\ 1969 & 6.103 & 5.383 \\ 1970 & 5.482 & 6.114 \\ 1971 & 3.365 & 10.112 \\ 1972 & 3.423 & 6.433 \\ 1973 & 8.775 & 2.656 \\ 1974 & 12.200 & 5.105 \\ 1975 & 7.013 & 5.399 \\ 1976 & 4.822 & 7.604 \\ 1977 & 6.769 & 8.255 \\ 1978 & 9.032 & 4.278 \\ 1979 & 13.319 & 6.638\end{array}$

Note: Calculations described in text. Yearly values were calculated on a December to December basis. 
was because the sharp increeses in real interest rates reduced the price of future consumption. Increasing real interest rates contributed $-7.1 \%$ in 1974 , $-4.7 \%$ in 1978 , and $-6.7 \%$ in 1979 to the intertemporal inflation rate. Overall, the correlation between the rate of inflation as measured using the standard CPI, and as measured using the interterporal index was only .45 .

These crude calculations indicate the irportance of aberesate factors other than the price level which way affect consurers' well being.

It is important to be clear about the levitisate uses of an intertemporal price index like the one developed here. The index provides a correct basis for assessing the change in welfare for a given change in prices and interest rates for an individual who has no future income streans. Even here there is a small problem unless individuals are infinite lived, since the lent th of their horizon is changing. The more serious issue involves future incowes. It would be appropriate to co:pare the present value of future incoses to the price index develoyed here. It should be clear that in such a calculation, the effects of a change in the interest rate on the present value of future streams, and on the price of future consumption would work in opposite directions. The adjustments under consideration will be important only when the duration of the individual's future consumption and income streass differ significantly. The data in Hurd and Shoven (1982) suggest that only about half of the wealth of the "young aeed" is in the form of future streams of income. This suggests that the price index considered here is likely to be very relevant to assessing their well being.

Once one conterplates the possibility of indexing benefits to a price index of this general type, other possibilities suggest therselves. Why not also index benefits to changes in real wealth wich also change the opportunity set, 
or to developwents which affect future incose? Erforts to intesrate private pensions and Social Security represent one snall step in this direction. Such indexing scheres of course involve the sare issues of discretion and capital rarket behavior. It does seem clear however that there is no strong logic which supports indexation of benefits to the current price level as against other alternatives.

A second implication of these results is that in making portfolio choices the aged should be concerned about real returns relative to an intertemporal price index like that considered here. Assets should be more highly valued if their returns are positivelj correlated with the price of future consumption. 


\section{Conclusions}

The analysis in this paper. supports three principal conclusions: First, indexation of both public and private pensions is likely to have only ninor efrects on real economic behavior. The presence of provisions for discretionary adjustment, and the workings of capital warkets, sugest that indexation provisions will be largely neutralized by other offsetting adjustivents.

Second, the effects of increased indexation may well be perverse. The precorvitment aspect of public indexing means that the ultirate effect of indexing provisions ray be to reduce the size of public pensions. The ror-indexation of private pensions probably represents efficient risk sharing. It appears that pension beneficiaries are much better bedged against inflation risks than are the bearers of pension liabilities.

Third, if insurance is the motivation for indexation provisions, there is no reason why such provisions should be confined to inflation. Only under very restrictive assumptions will inflation indexing provide full insurance. In particular an important source of exogenous uncertainty facing the aged involves the price of future consumption. Changes in an estinated interteiporal cost of living index diverge significantly from those in the conventional CPI.

Robert Merton, in his contribution to this volume advocates a novel solution to.some of the problems discussed here. He proposes that Social Security benefits be indexed to the level of aggregate consumption. He argues that in addition to providing inflation protection, such a plan would offer a form of "standard of living" insurance. In general, the level of consumption is likely to be a proxy for the opportunity set facing consumers. This notion is justified formally in Merton (1973) and Breeden (1979). 
Merton's proposed Social Security plan is self financing and requires only very infrequent adjustuent. The self financing character of the plan reduces substantially the precomitment problens stressed here. lierton's indexing scheme provides for both increases and decreases in benefit levels, so the "no cut" constraint is unlikely to bind. It also implicitly nakes benefit levels depend on both the level of wealth and real rates of return.

There are however a number of types of shocks which are likelj to affect real consurption but not optimal benefit levels. These include changes in the taste for leisure, changes in demographic coiposition of the population, changes in life expectancy, and changes in the distribution of income. The iuportance of these shocks relative to others causing fluctuations in aggrebate consumption is an empirical question. If they are significant, it may be preferable to design indices based on estilated changes in the opportunity set of the representative aged consumer. The intertesporal cost of living index presented here represents a start in this direction. 
$-27-$

Footnotes

1. Indexing in the design of the benefit formula may well cause greater horizontal equity.

2. While the discussion here focuses on Social Security, it is clearly applicable to other public pensions such as those for veterans and federal employees.

3. This condition is necessary. In order to meaningfully talk about the effects of indexation it must be assumed that benefit packages have equal value in all cases. 


\section{References}

Advisory Council on Social Security, Report of the 1979 Advisory Council on Social Security, reprinted by the Committee on hays and Means, WMCP: $96-45$, $96 \mathrm{th}$ Congress, -1st Session, Jan. 2, 1980.

Bodie, Zvi, "Investment Strategy in an Inflationary Environment," NBER Working Paper No. 442, 1981.

Breeden, Douglas, "An Intertemporal Asset Pricing Model with Stochastic Consumption and Investrent Opportunities," Journal of Financial Economics, 1979.

Blume, Marshall, Jean Crockett and Ixwin Friend, "Stock Ownership in the United States: Characteristics and Trends," Survey of Current Business, November 1974 .

Bulow, Jeremy, "Analysis of Pension Funding Under ERISA," forthcoming in Quarterly Journal of Economics, 1982.

Carlson, John A., "A Study of Price Forecasts," Annals of Economic and Social Measurement, June 1977, PP. 27-56.

Feldstein, Martin, "Should Private Pensions be Indexed?" NBER Working Paper No. 787, 1981 .

Hurd, Michael and John Shoven, "The Economic Status of the Elderly," 1982.

Liviatan, N., and D. Levhari, "Risk and the Theory of Indexed Bonds," Amer. Econ. Rev., 67(3), June 1977, Pp. 366-75.

Litterman, R., "Bayesian Vector Autoregressive Forecasts," mimeo, 1980.

Merton, Robert, "An Intertemporal Capital Asset Pricing Model," Econometrica, 1973.

-.-.-. "A Proposal for a Public Pension Plan," 1982.

Mullineawx, D., "Testing Rationality of Inflation Expectations," Journal of Political Economy, 1979.

Pesando, James E., "A Note on the Rationality of the Livingston Price Expectations," Journal of Political Economy, August 1975.

Pollak, Robert A., "The Intertemporal Cost of Living Index," Ann. Econ. Soc. Measure., 4, 1, Winter 1975, PP. 179-195.

Poterba, J., "Inflation, Income Taxes and Owner-Occupied Housing," NBER Working Paper No. 553, 1981. 
President's Corynission on Pension Poljcy Sumary Keport, 1980.

Sims, Christopher, "Macroeconomics and Reality," Economelr1ca, January 1980.

Sumpers, Lawrence H., "Inflation, the Stock Market and Owner Occupied Housing," American Economic Keview, vol. 71, May 1981a.

......... "Inflation and the Valuation of Corporate Equities," NBER lorking Paper No. 824, 1981 b. 
</ref_section> 